\title{
Ecological and Health Risks Assessment of Potentially Toxic Metals and Metalloids (PTMMs) Contaminants
}

Mohammed Alsafran ${ }^{1,2}$, Kamal Usman ${ }^{1 *}$, Hareb Al Jabri² , Muhammad Rizwan ${ }^{3}$

${ }^{1}$ Agricultural Research Station, Office of VP - Research \& Graduate Studies, Qatar University, Doha, Qatar

${ }_{2}^{2}$ Department of Biological \& Env. Sci., College of Arts \& Sciences, Qatar University, Doha, Qatar

${ }^{3}$ College of Resources and Environment, Huazhong Agricultural University, Wuhan 430070, China

This study was published in Toxics 2021, 9(2), 35; https://doi.org/10.3390/toxics9020035

\section{Abstract}

- Human activities including agriculture cause PTMMs contamination

Results showed high cancer risks to humans due to Arsenic (As), Chromium (Cr) and Nickel (Ni) exposure

- Reducing PTMMs bioavailability and innovative remediation technologies are needed

Future work will investigate $\mathrm{As}, \mathrm{Cr}$, and $\mathrm{Ni}$ long-term exposure and gastrointestinal bioaccessibilities

PTMM's Sources

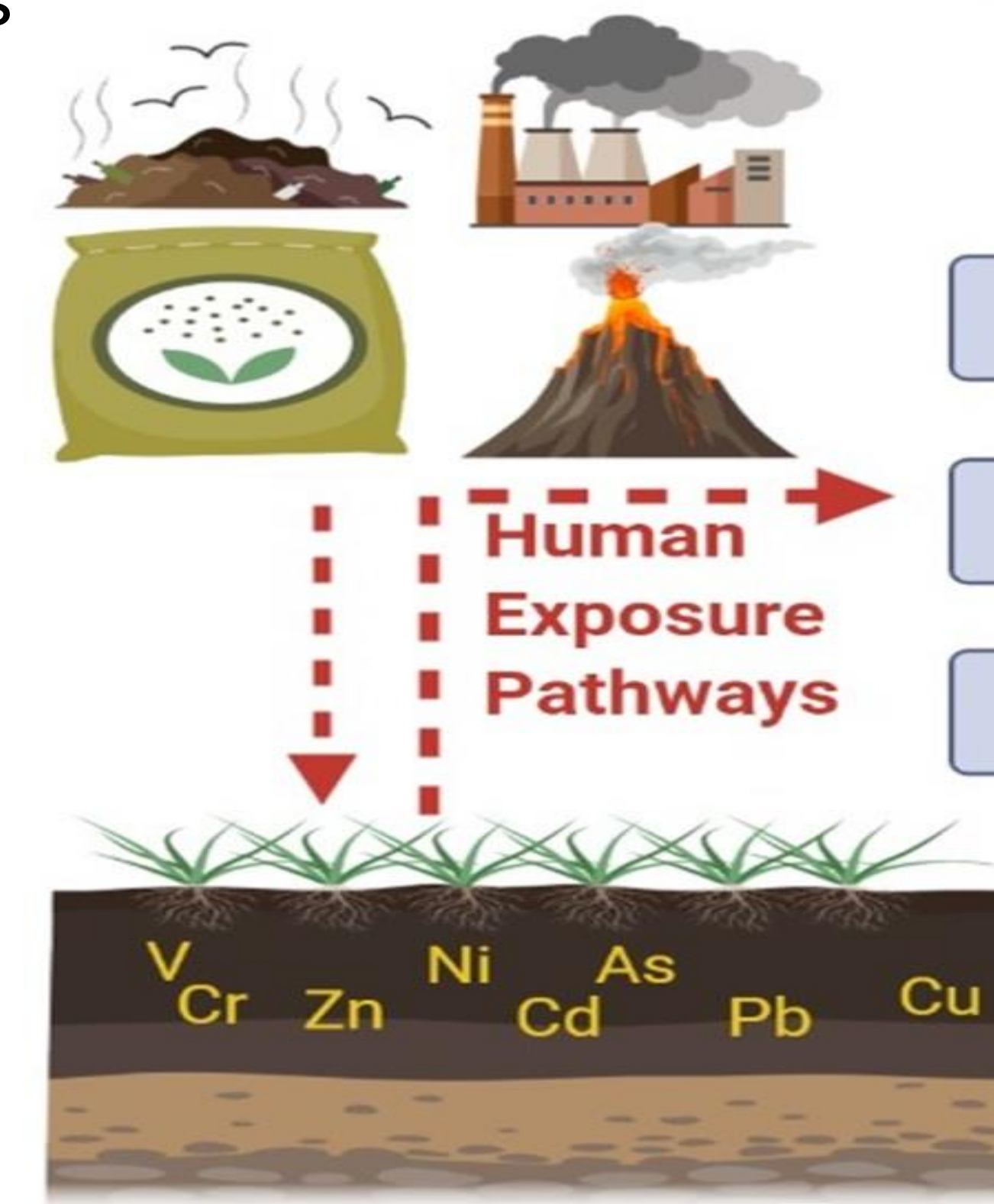

Accumulation in the Soil

\section{Study Background}

Previous studies by Usman et al., (2019) and Peng et al., (2016) suggest that soils in some industrial and cultivated areas of Qatar may be contaminated with potentially toxic metals and metalloids including arsenic, chromium, cadmium and nickel

Air

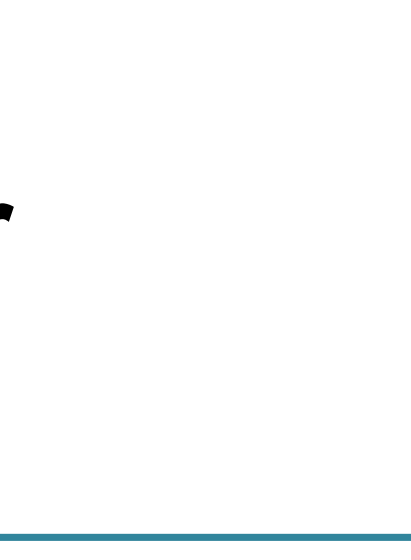

Soil

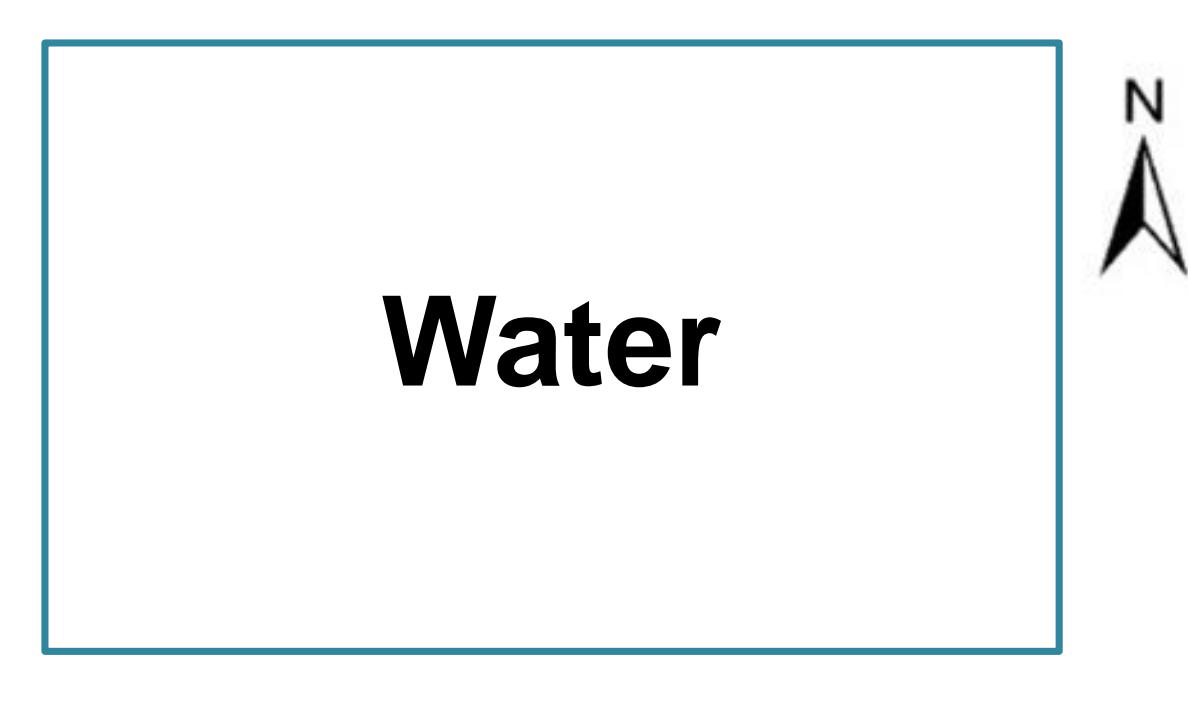

\section{Human health \\ problems e.g cancer}

Fig. 1. Potentially toxic metals the environments and synergistic effects on human health

\section{Objectives}

1. Analyze the physico-chemical composition of Agricultural soils in Qatar

2. Assess the level of potentially toxic metals and metalloids in the cultivated soils

3. Evaluate the potential ecological and human health risks associated with the metals exposure

\section{Methods Summary}

\begin{tabular}{|c|c|}
\hline $\begin{array}{c}\text { Metals } \\
\text { conc. }\end{array}$ & $\begin{array}{c}\mathrm{EC}, \mathrm{pH}, \\
\text { TOC, } \\
\text { Nutrients }\end{array}$ \\
\hline $\begin{array}{c}\text { Human } \\
\text { Health }\end{array}$ Ecologic. \\
\hline Physico- \\
chem.
\end{tabular}

Ecological Risk Evaluation

\section{Human Health Risk Evaluation}

$$
\begin{aligned}
& \mathrm{ADD}_{\text {ingestion }}=\frac{\mathrm{C}_{\text {soil }} \times \operatorname{IngR} \times \mathrm{EF} \times \mathrm{ED}}{\mathrm{BW}_{\mathrm{A}} \times \mathrm{ET}_{\mathrm{A}}} \times 10^{-6} \\
& \mathrm{ADD}_{\text {dermal }}=\frac{\mathrm{C}_{\text {Soil }} \times \mathrm{ESA}_{\mathrm{A}} \times \mathrm{ABS}_{\mathrm{A}} \times \mathrm{AF}_{\mathrm{B}} \times \mathrm{EF} \times \mathrm{ED}}{B \mathrm{BW}_{\mathrm{A}} \times \mathrm{ET}_{\mathrm{A}}} \times 10^{-6} \\
& \mathrm{ADD}_{\text {inhalation }}=\frac{\mathrm{C}_{\text {soil }} \times \text { InhR } \times \mathrm{EF} \times \mathrm{ED}}{\mathrm{BW}_{\mathrm{A}} \times \mathrm{ET}_{\mathrm{A}} \times \mathrm{EF}_{\mathrm{P}}} \\
& \mathrm{HI}=\sum \mathrm{HQ}_{\mathrm{i}}=\sum \frac{\mathrm{ADD}_{\mathrm{i}}}{\mathrm{RfD}_{\mathrm{i}}} \\
& \mathrm{CR}_{\text {inhalation }}=\frac{\mathrm{C}_{\text {soil }} \times \operatorname{InhR} \times \mathrm{EF} \times \mathrm{ED}}{\mathrm{BW}_{\mathrm{A}} \times \mathrm{ET}_{\mathrm{Ca}} \times \mathrm{EF}_{\mathrm{P}}} \times \mathrm{SF}_{\text {inhalation }} \\
& \mathrm{CR}_{\text {dermal }}=\frac{\mathrm{C}_{\text {soil }} \times \mathrm{ESA}_{\mathrm{A}} \times \mathrm{ABS} \times \mathrm{AF}_{\mathrm{F}} \times \mathrm{EF} \times \mathrm{ED}}{\mathrm{BW}_{\mathrm{A}} \times \mathrm{ET}_{\mathrm{A}}} \times 10^{-6} \times \mathrm{SF}_{\text {dermal }} \\
& \mathrm{CR}_{\text {ingestion }}=\frac{\mathrm{C}_{\text {soil }} \times \operatorname{lng} \times \mathrm{EF} \times \mathrm{ED}}{\mathrm{BW}_{\mathrm{A}} \times \mathrm{ET}_{\mathrm{Ca}}} \times 10^{-6} \times \mathrm{SF}_{\text {ingesstion }} \\
& \mathrm{TCR}=\sum\left(\mathrm{CR}_{\text {ingestion }}+\mathrm{CR}_{\text {dermal }}+\mathrm{CR}_{\text {inhalation }}\right)
\end{aligned}
$$

\section{Sample Results}

- High As, $\mathrm{Cr}$, and Ni contamination (CF > 1) poses ecological risk
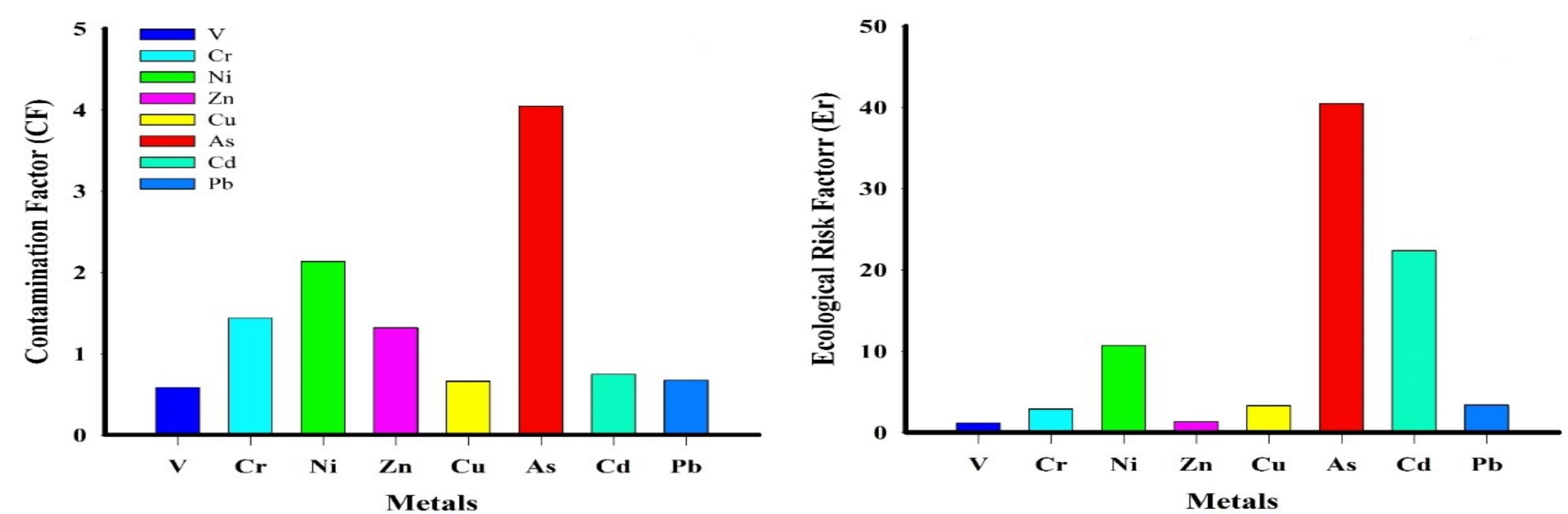

Geo-accumulation index (Igeo) of up to 2.5, and enrichment factor (EF $>1$ ) indicates that up to $58 \%$ of the soil is contaminated due to human activities including agriculture
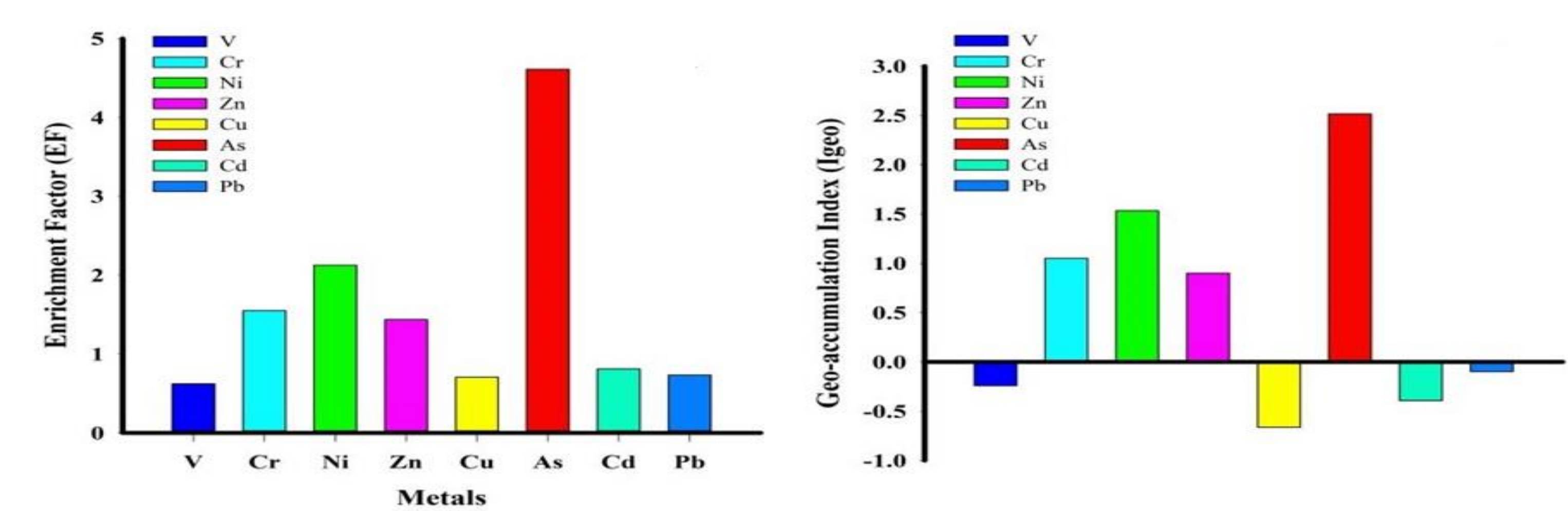

As, $\mathrm{Cr}$, and $\mathrm{Ni}$, with total carcinogenic risk (TCR $=1.18 \times 10-4$ and $2.06 \times 10-4)$ indicates cancer risks to humans
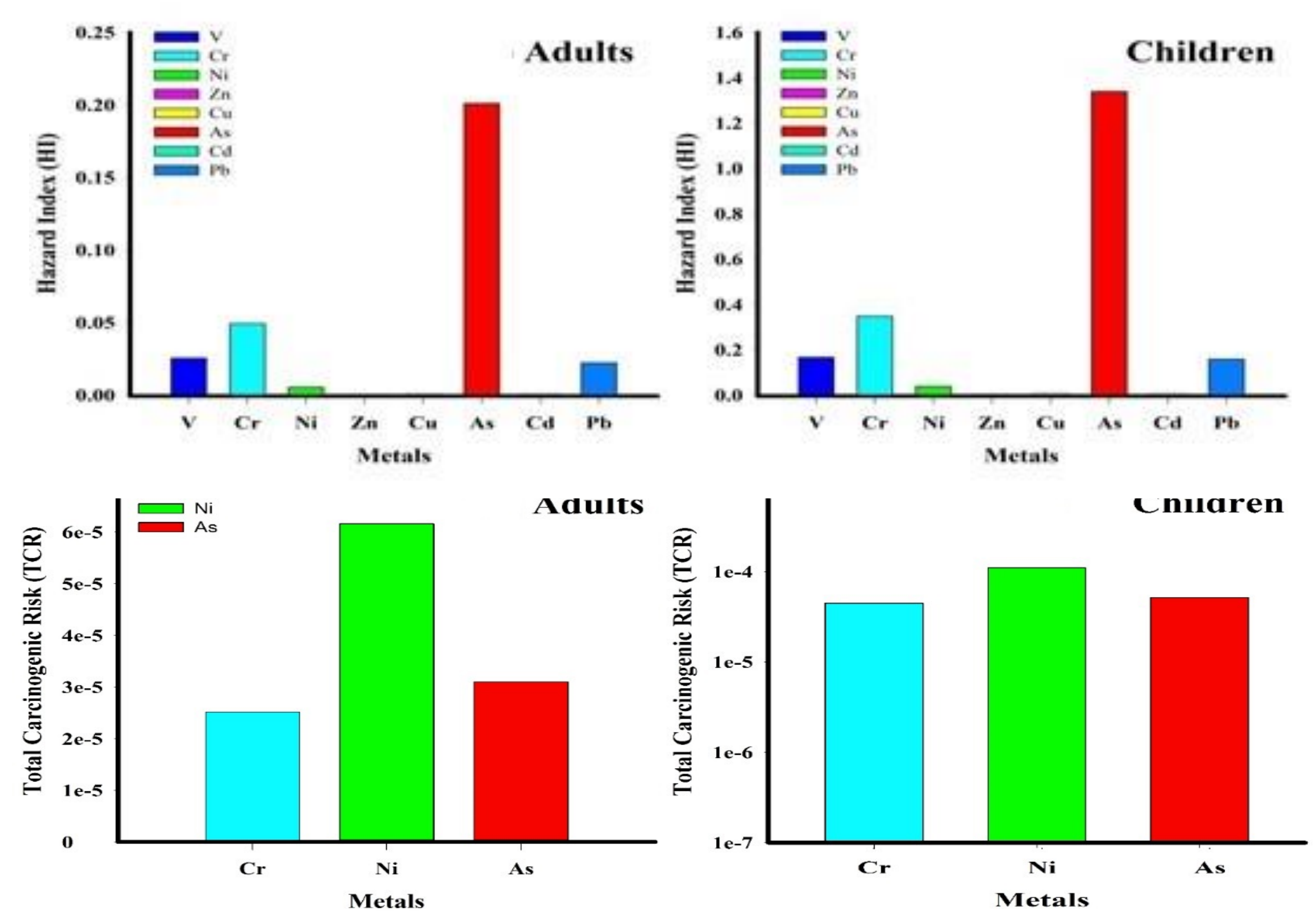

Fig. 2. Summarized results of (A) Contamination/Ecological risk factors (B) Enrichment factor/ Geo-accumulation index (C) Hazard index and (D) Carcinogenic/Total carcinogenic risks Conclusion/Future Work

1. Arsenic, chromium, and nickel concentrations are significantly higher than USEPA limits in the studied agricultural soils

2. The elements poses ecological and human health (carcinogenic and noncarcinogenic) risks

3. Oral ingestion is the principal exposure pathway in both adults and children

4. Children are the most vulnerable to the elements toxic effects, and likely to develop cancer over due to As and Ni exposure

5. Further studies on $\mathrm{As}, \mathrm{Cr}$, and $\mathrm{Ni}$ gastrointestinal bio-accessibilities are needed to fully understand the long-term exposure effects and the cancer-causing potential of these elements over a lifetime

\section{Selected References}

1. Peng, Y. et al., (2016). Digital mapping of toxic metals in Qatari soils using remote sensing and ancillary data. Remote Sensing, 8, 1003.

2. Risk assessment guidance for superfund; Office of Emergency and Remedial Response, US Environmental Protection Agency: 1989; Vol. 1.

\section{Acknowledgement}

This work was funded by the QU vegetable factory project: QUEX-CAS-MJF2018/2019 with support from MARUBENI. All elemental analysis were performed at the Central Laboratories Unit (CLU). Authors are appreciative of Dr. Mohammad lbrahim's support in the course of this work 